\title{
An Experimental and Numerical Study of the Load Distribution Effect on Composite Slab Shear Resistance
}

\author{
Milad Soltanalipour, Miquel Ferrer, Frederic Marimon \\ Dept. of Strength of Materials and Structural Engineering, Universitat Politècnica de Catalunya BarcelonaTech (UPC), \\ Barcelona, Spain \\ Email: Miquel.ferrer@upc.edu \\ Josef Holomek, Miroslav Bajer \\ Faculty of Civil Engineering, Brno University of Technology, Brno, Czech Republic \\ Email: Holomek.j@fce.vutbr.cz
}

\begin{abstract}
The design codes prescribe "a close simulation" of the uniformly distributed loads for bending tests, since, applying an ideal uniform load on the slab surface, is not technically as simple as applying concentrated loads by spreader beams. The 4-point bending test used in both standard methods m-k and PCM to determine the shear resistance of composite slabs is currently the most conventional loading arrangement. This article presents the comparison between the 4-point bending and uniform load results, obtained from both experimental tests and numerical simulations. Two groups of specimens, made with a common trapezoidal steel profile and concrete, including short and long spans, have been tested under the two loading setups. The numerical analysis of these slabs has been carried out through modelling the realistic interaction of steel and concrete. For the 4-point bending simulation, predefined vertical cracks are modelled representing the real crack inducers, whereas, for the uniform load case, the Willam-Warnke model is used. Both the experimental and the numerical results indicated that the 4-point bending test provides higher shear strength than uniform load. The experimental part was conducted by LERMA (Universitat Politècnica de Catalunya - BarcelonaTech) in collaboration with AdMaS-BUT at Brno University of Technology. The 3D FEM of composite slabs has been made through ANSYS software.
\end{abstract}

Index Terms- composite slabs, uniformly distributed loading, m-k 4-point bending, longitudinal shear resistance

\section{INTRODUCTION}

Steel and concrete, two constituent materials with different structural properties when combined generate a composite structure with entirely new properties. A typical composite slab shown in Fig. 1 consists of cast-inplace concrete and the steel profile, acting as a shuttering for the concrete during the construction stage. Once the concrete hardens it combines structurally with the profile sheet to form a composite member. Recently, a new generation of sheeting designs providing the perfect bond between concrete and steel until both materials yield, has been introduced [1]. However, the embossments are the conventional interlocking systems in today construction and there is a significant research studying their geometrical effect on longitudinal shear resistance. In terms of shape, the steel profiles are divided into three groups: trapezoidal, re-entrant and combined. Trapezoidal profiles are the mostly used due to their capacity to span larger distances and to economize steel and concrete than re-entrant profiles, however, their ductility is lower in terms of longitudinal shear strength. This work focuses on a conventional $60 \mathrm{~mm}$ high trapezoidal profile.

There are two methods prescribed by Eurocode-4 [2] the $\mathrm{m}-\mathrm{k}$ and the partial connection method (PCM), used to determine the slab resistance to longitudinal shear. These evaluation methods can be used for whether 4point bending or uniform load test setups. In Eurocode-4, the technical rules and requirements of 4-point bending test are described, but the uniform load requirements are partially pointed. In that case, the British Standard 5950 [3] prescribes "a close simulation" of the uniformly distributed loads as 6-point bending test. Probably it is recommended instead of applying an ideal uniform load on the slab surface because it is not technically as simple as applying concentrated loads through spreader beams. On the other hand, the strength requirements are also specified in terms of uniform load by design codes. Different methods have been used in research background to implement the uniform load setup, such as the 6-point bending, uniform loading through progressively adding small weights, the vacuum chamber or the air bag loading systems.

Lopes [4] carried out experimental test including a combination of the distributed load and mid-span line load, in order to verify the analytical formulations developed as "a new simplified method" [5]. The uniform load was applied by adding small concrete cubes manually. 


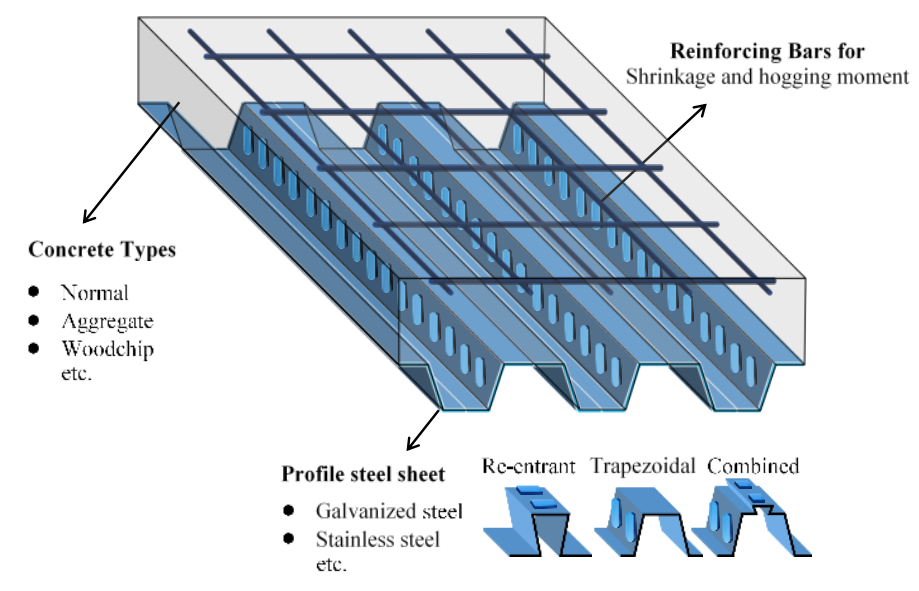

Figure 1. Typical composite slab

The loading had three stages: first, application of distributed and concentrated loads until the load serviceability limit state, second, increasing both loads until the ultimate limit state, third, increasing only the concentrated line load until the slab failure.

Veljkovic [6] used 2D FE models with nodal interface elements to study the influence of load arrangement on slab behavior. The load arrangements include 6-, 10- and 18-point bending and the resistance of specimens has been reported $20 \%, 30 \%$ and $40 \%$ higher than the standard 4-point bending, respectively. The shortcoming of $2 \mathrm{D}$ model is that because the steel sheeting was modelled as beam element and the shear deformation is neglected in Bernoulli beam theory, the 2D models predicts larger vertical forces compared with the more realistic 3D model. The mechanical interlocking resistance and friction between steel and concrete was modelled with the results from small-scale tests.

G. Shen [7] used the rubber airbag loading system to study the performance of composite slabs with a corrugated-type indentation. The airbag has two valves: one connected to the air-hose to input the pressure, and the other connected to a calibrated pressure transducer, which measures the pressure in the airbag. A steel test frame bolted to the reaction floor, resisted the pressure from the airbag. Sheets of plywood were placed between the airbag and the test frame to distribute the pressure. In this research, the purpose was not studying the load setup effect but profile sheeting properties.

J. Holomek [8] used uniform area loading by vacuum testing device in AdMaS centre of BUT. [9] The device is the designed based on several decades of experiences with vacuum testing of various materials and structures of prof. Melcher and prof. Karmazínová. [10] The system comprises of a hermetically isolated space under the specimen, from which the air is pumped out. The pressure load on the slab is the difference between inside the vacuum chamber and outside atmospheric pressure. This system produces an ideally distributed area load on the slab surface, transferred through a plastic foil. The vertical shear resistance in vacuum loading was reported to be higher than that of 4-point bending. Notably, the slabs were made without support in the middle of span during the concreting.

J. Rios [11] studied a set of 6-point bending tests and FE models. The profiled sheeting was the same used in a similar article related to 4-point bending test [12] but the ultimate strengths in two test setups were not compared, because of the different slenderness and shear lengths. There is an intuitive conclusion that the bending cracks are depicted only in 6-point test.

Based on the state of the art, it is difficult to present a comparison between 4-point bending and uniform load results. Hence, in this article a specific experimental and numerical study is programmed with regard to the following points:

$\checkmark$ Similar sheeting design and slab slenderness

$\checkmark$ Realistic 3D-contact behavior between materials

$\checkmark$ Full-scale tests of short and long slabs to pursue the provisions of Eurocode 4 [2]

\section{BENDING TESTS \\ (4-POINT BENDING AND UNIFORM LOAD TESTS)}

The test program consists of the 12 steel-concrete composite slabs presented in Table 2. A commercial trapezoidal profile with conventional embossments is used. The profile cross-section geometry is illustrated in Fig. 3 and the mechanical properties of steel and concrete are presented in Table 1.

The 4-point bending test consists of two equal concentrated line loads located at L/4 and 3L/4 on the span, whereas the vacuum chamber produces an ideally distributed pressure on the slab surface, transferred through a plastic foil cover. The experimental images of test setups are presented in Fig. 5. For both test setups, the application of static and cyclic loads is according to the Eurocode 4 specifications; the strength $W_{t}$ of the first static test, gives the lower and upper limits, $0.2 W_{t}$ and $0.6 W_{t}$ respectively, of the two following cyclic tests. 
TABLE I. Mechanical Properties of THE Materials

\begin{tabular}{ccccc}
\hline & Steel & & $\begin{array}{c}\text { Concrete } \\
\text { (in } 4 p \text { test) }\end{array}$ & $\begin{array}{c}\text { Concrete } \\
\text { (in } \text { Unif test) }\end{array}$ \\
\hline $\begin{array}{c}f_{\boldsymbol{y}} \\
{[\mathrm{MPa}]}\end{array}$ & $\begin{array}{c}\boldsymbol{f}_{\boldsymbol{u}} \\
{[\mathrm{MPa}]}\end{array}$ & $\begin{array}{c}\text { Thickness } \\
{[\mathrm{mm}]}\end{array}$ & $\begin{array}{c}\boldsymbol{f}_{c k} \\
{[\mathrm{MPa}]}\end{array}$ & $\begin{array}{c}\boldsymbol{f}_{c k} \\
{[\mathrm{MPa}]}\end{array}$ \\
\hline 326 & 422 & 0.74 & 25.1 & 34.2 \\
\hline
\end{tabular}

TABLE II. Test PRogram

\begin{tabular}{cllcccccc}
\hline Group & Specimen & $\begin{array}{c}\boldsymbol{L} \\
{[\mathrm{mm}]}\end{array}$ & $\begin{array}{c}\boldsymbol{L}_{\boldsymbol{o}} \\
{[\mathrm{mm}]}\end{array}$ & $\begin{array}{c}\boldsymbol{L}_{\boldsymbol{s}} \\
{[\mathrm{mm}]}\end{array}$ & $\begin{array}{c}\boldsymbol{b} \\
{[\mathrm{mm}]}\end{array}$ & $\begin{array}{c}\boldsymbol{h}_{\boldsymbol{c}} \\
{[\mathrm{mm}]}\end{array}$ & Load type & Load distribution \\
\hline \multirow{3}{*}{ A } & Short-4p\#1 & 2600 & 100 & 600 & 820 & 100 & Static & 4-point bending \\
\cline { 2 - 9 } & Short-4p\#2 & 2600 & 100 & 600 & 820 & 100 & Cyclic + static & 4-point bending \\
\cline { 2 - 9 } & Short-4p\#3 & 2600 & 100 & 600 & 820 & 100 & Cyclic + static & 4-point bending \\
\hline \multirow{3}{*}{ B } & Long-4p\#1 & 5200 & 100 & 1250 & 820 & 200 & Static & 4-point bending \\
\cline { 2 - 9 } & Long-4p\#2 & 5200 & 100 & 1250 & 820 & 200 & Cyclic + static & 4-point bending \\
\cline { 2 - 9 } & Long-4p\#3 & 5200 & 100 & 1250 & 820 & 200 & Cyclic + static & 4-point bending \\
\hline \multirow{3}{*}{ C } & Short-unif\#1 & 2600 & 100 & 600 & 820 & 100 & Static & Uniform \\
\cline { 2 - 9 } & Short-unif\#2 & 2600 & 100 & 600 & 820 & 100 & Cyclic + static & Uniform \\
\cline { 2 - 9 } & Short-unif\#3 & 2600 & 100 & 600 & 820 & 100 & Cyclic + static & Uniform \\
\hline \multirow{3}{*}{ D } & Long-unif\#1 & 5200 & 100 & 1250 & 820 & 200 & Static & Uniform \\
\cline { 2 - 9 } & Long-unif\#2 & 5200 & 100 & 1250 & 820 & 200 & Cyclic + static & Uniform \\
\cline { 2 - 8 } & Long-unif\#3 & 5200 & 100 & 1250 & 820 & 200 & Cyclic + static & Uniform \\
\hline
\end{tabular}

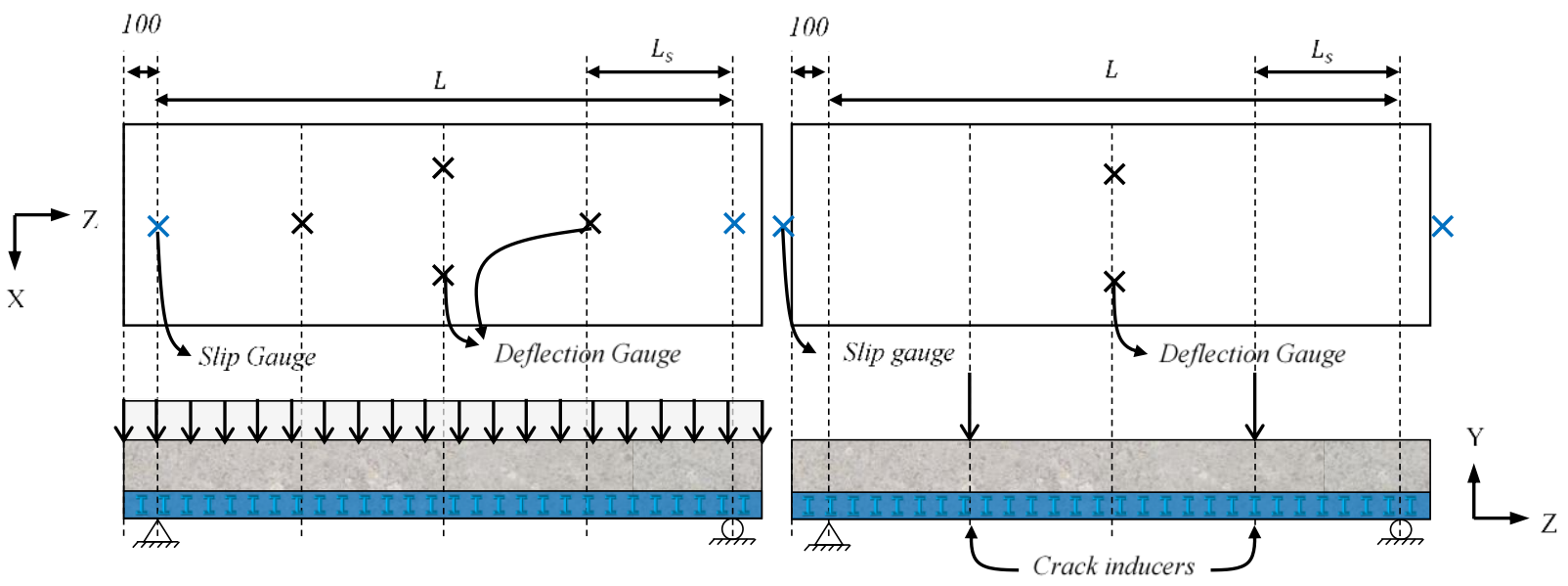

Figure 2. Arrangement of deflection and slip transducers in both test setups [mm]

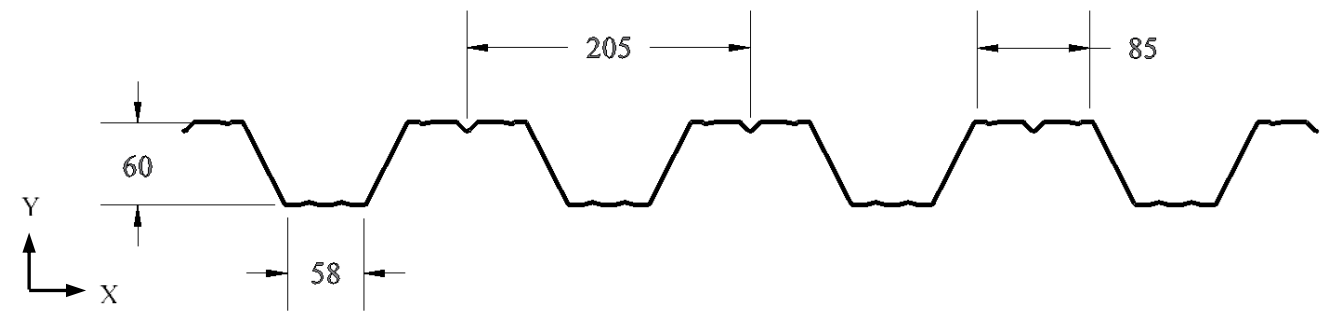

Figure 3. Profile cross-section geometry $[\mathrm{mm}]$ 
After cycling, second and third specimens were statically and monotonically loaded until failure. The failure mode in all specimens is longitudinal shear, depicted by the slip of the concrete over the sheeting. The longitudinal shear resistance is calculated based on the $m$ $k$ method through the Equation 1:

$$
V_{l, R d}=b d_{p}\left(\left(m A_{p} / b L_{s}\right)+k\right)
$$

Where, $b$ is the slab width, $d_{p}$ is the distance between the centroidal axis of the profiled steel sheeting and the upper fiber of the concrete, $A_{p}$ is the cross-sectional area of sheeting and the shear span length is $L_{S}=L / 4$ in both loading arrangements as prescribed in Eurocode-4, based on the concept of equivalent areas of vertical shear diagrams. The empirical $m$ and $k$ parameters are determined as the slope and the intercept of the regression line, respectively, as shown in Fig. 4 and Table III.

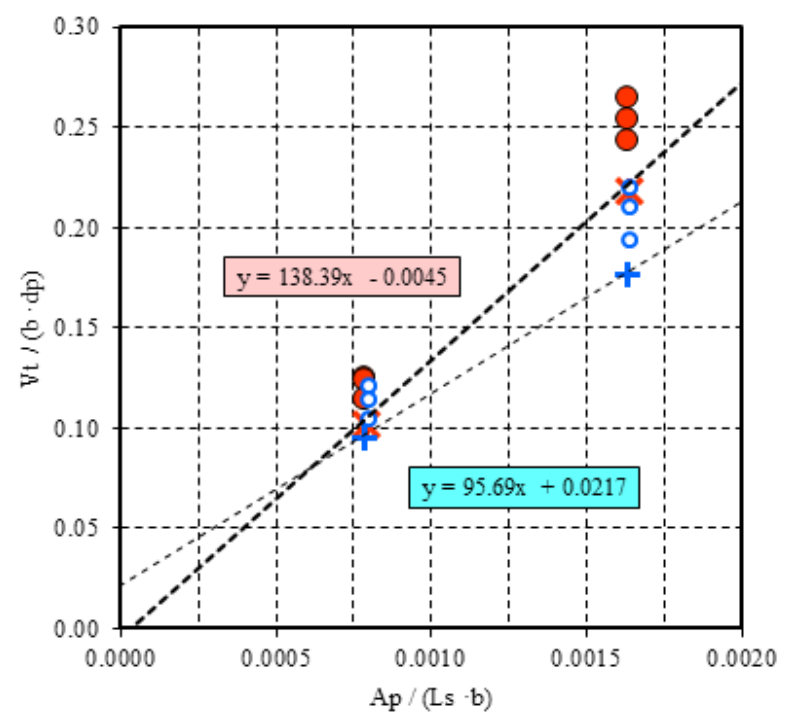

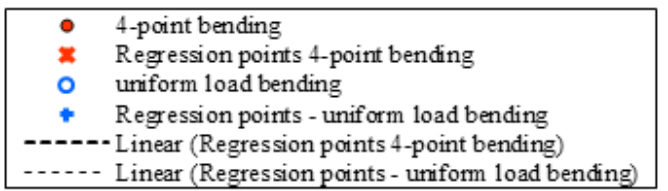

Figure 4. Design relationship

TABLE III. $M$ AND $K$ VALUeS For Both TeSt SETUP

\begin{tabular}{ccc}
\hline & $\boldsymbol{m}$ & $\boldsymbol{k}$ \\
& {$[\mathrm{MPa}]$} & {$[\mathrm{MPa}]$} \\
\hline Standard $m-k$ test & 138.38 & -0.0045 \\
\hline Uniform load test & 95.69 & 0.0217 \\
\hline
\end{tabular}

The arrangement of slip and deflection transducers is illustrated in Fig. 2. In uniform load setup, installing the slip gauges at the slab ends was not practically possible because of the polystyrene surrounding the specimens. Therefore, the transducers were implemented below the slab to measure the relative movement of concrete and steel, as shown in Fig. 5 C.

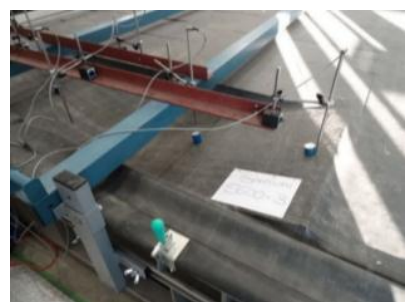

A)

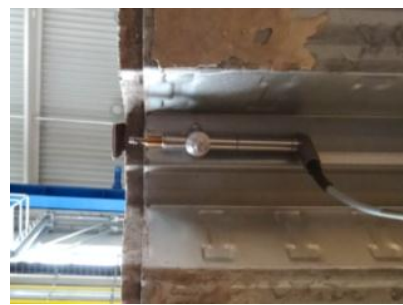

C)

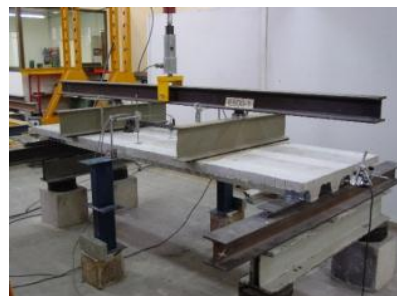

B)

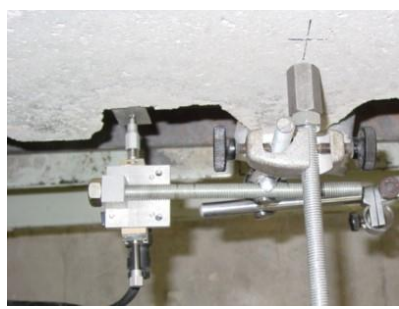

D)
Figure 5. Test setup: A) B) and Slip Gauges: C) D)

It must be pointed that, after passing the peak load, maintaining a uniform distribution of pressure on the whole slab upper surface is technically impossible because of the plastic foil detachment. Thus, the calculation of the reaction force $W_{t}$ from the applied pressure is not reliable after the peak load. Currently, it has been solved for applying uniform load in higher deflections.

\section{FE MODELS AND DISCUSSIONS}

The shear resistances obtained from the finite element models are compared between uniform and 4-point loading, independently form experimental results, in order to verify if the different resistances are depicted in numerical analysis too. On the other hand, the FEM results are extraordinarily useful to evaluate and understand the origin of that difference. The ANSYS ${ }^{\circledR}$ v19 software has been used for finite element modelling.

Higher order elements SOLID187 [13] are used for modelling the concrete under 4-point bending, together with a discrete crack approach. For the uniform load case, the concrete element type SOLID65 [13] with cracking and crushing capabilities is used (see Fig. 6). The element type SHELL281 [13], which is well-suited for large strain nonlinear applications (see Fig. 7), is used for steel with a bilinear stress-strain curve. The interaction between steel and concrete is achieved by modeling the detailed geometry of embossments and contact elements. The friction coefficient, representing the high punctual interaction forces that includes eroding contact phenomenon (see Fig. 8), takes a higher value than 0.5 which is conventionally used for flat surface contact. After a series of FE trials, the value of $\mu=0.8$ has been determined as a good representative for such a tough contact between concrete and steel for this particular embossment design. 


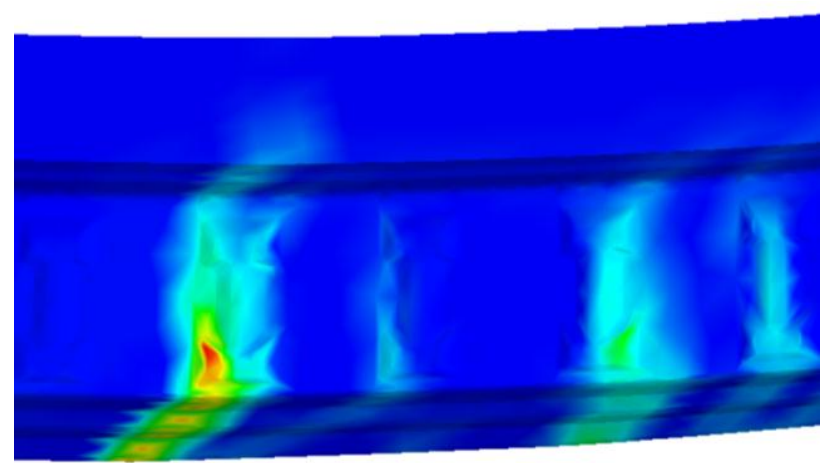

Figure 6. Concrete cracking in uniform loading

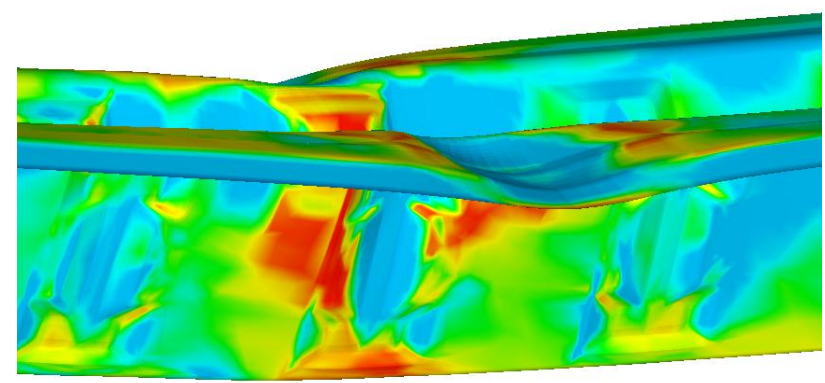

Figure 7. Sheeting local buckling in 4-point bending

In 4-point bending simulation, the vertical predefined cracks provoked in the real tests by the crack inducers, are modelled through a discontinuous plane on the concrete mesh. Then, the nodes lying on the upper surface shared by the two concrete blocks are merged to let the compressive bending forces being transferred. This concrete cracking approach has shown to accurately reproduce both the short and long span specimens bending behavior under 4-point bending (see Fig. 9 B). Additional models with crackable elements SOLID65 were also made to verify the results.

In uniform load modeling, the smeared cracking behavior of concrete (see Fig. 6 and Fig. 9 D) has been used including the Willam-Warnke failure criterion. The arc-length method has been used to control the instability of model after cracking.

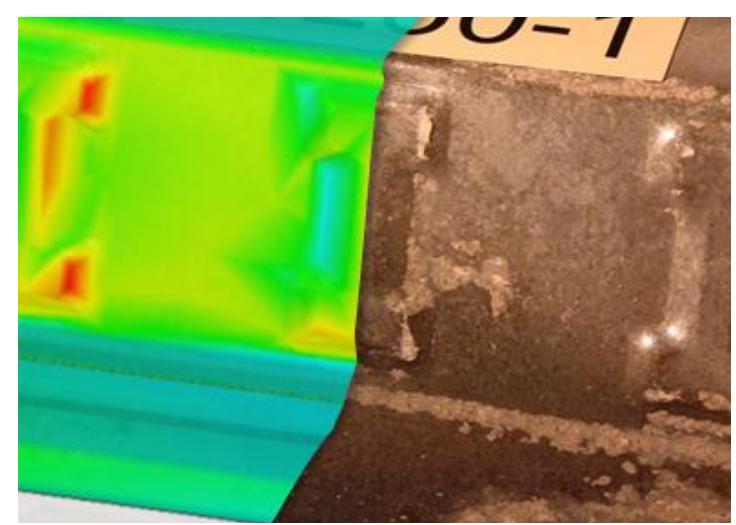

Figure 8. Experimental and FE simulation of contact eroding process

Three symmetry boundary conditions have been used: the conventional longitudinal symmetry at the midspan and two lateral symmetries on the sides of the rib. Thus, only a half-span single rib is modeled.

The obtained shear-deflection curves (blue-thick lines), presented Fig. 10, show a good consistency with the 4point (4p) and uniform (Unif) loading test results (greythin lines). The end points of the FEM curves are due to either the crushing of the concrete on the upper surface and/or the vertical release of concrete block from the sheeting.

The shear resistance ratios between uniform and 4point loading are presented in Table 4, for both numerical and experimental results. The 4-point models, even with predefined open cracks, showed higher resistances than the uniform models.

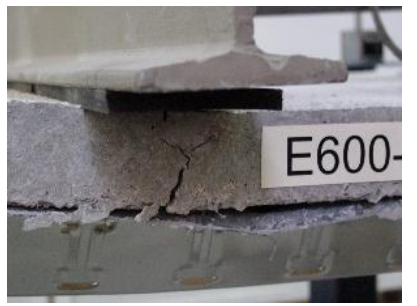

A)

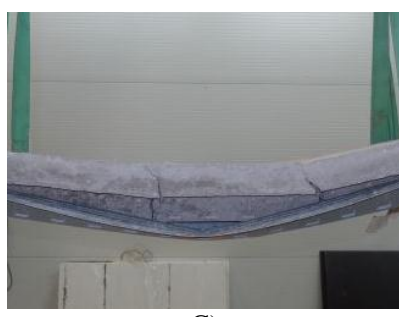

C)

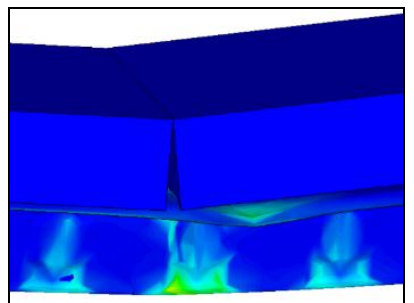

B)

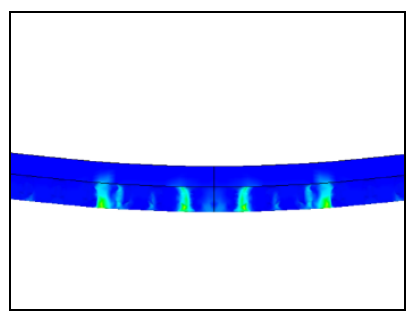

D)
Figure 9. Experimental cracking A) C) and the corresponding FEMs B) D)

TABLE IV. RESISTANCE RATIOS

\begin{tabular}{rlcc} 
& & \multicolumn{2}{c}{ Resistance ratio* } \\
\cline { 2 - 3 } & & TEST & FEM \\
\hline \multirow{3}{*}{$\begin{array}{c}\text { Short } \\
\text { span }\end{array}$} & Max. & \multirow{2}{*}{$\mathbf{0 . 6 9}$} \\
\cline { 2 - 3 } & Med. & 0.82 & \\
\cline { 2 - 3 } & Min. & 0.78 & \\
\cline { 2 - 3 } Long & Avg. & $\mathbf{0 . 8 0}$ & \multirow{2}{*}{$\mathbf{0 . 9 3}$} \\
\cline { 2 - 3 } span & Max. & 0.97 & \\
\cline { 2 - 3 } & Med. & 0.94 & \\
\cline { 2 - 3 } & Min. & 0.93 & $\mathbf{0 . 9 5}$ \\
\hline
\end{tabular}

$*$ Resistance Ratio $=\frac{\text { Eqv. } F_{c y l}(\text { unif })+W_{\text {slab }}}{F_{c y l}(4 \text { point })+W_{\text {slab }}+W_{\text {loadbeam }}}$

\section{CONCLUSIONS}

From the experimental descriptions and FE analysis the following results derives:

- The resistance ratios reveal higher strengths for 4point load arrangement.

- The strength differences are much more significant for short slabs than for long spans, as shown in Fig. 4 and Table IV. 
- The 4-point bending curves are more ductile than the uniform load curves. I0t probably derives from the absence of crack inducer in the uniform load case.

Further experimental/numerical research is being developed to figure out the reasons for having different shear resistances on the same slabs depending on the load arrangement.
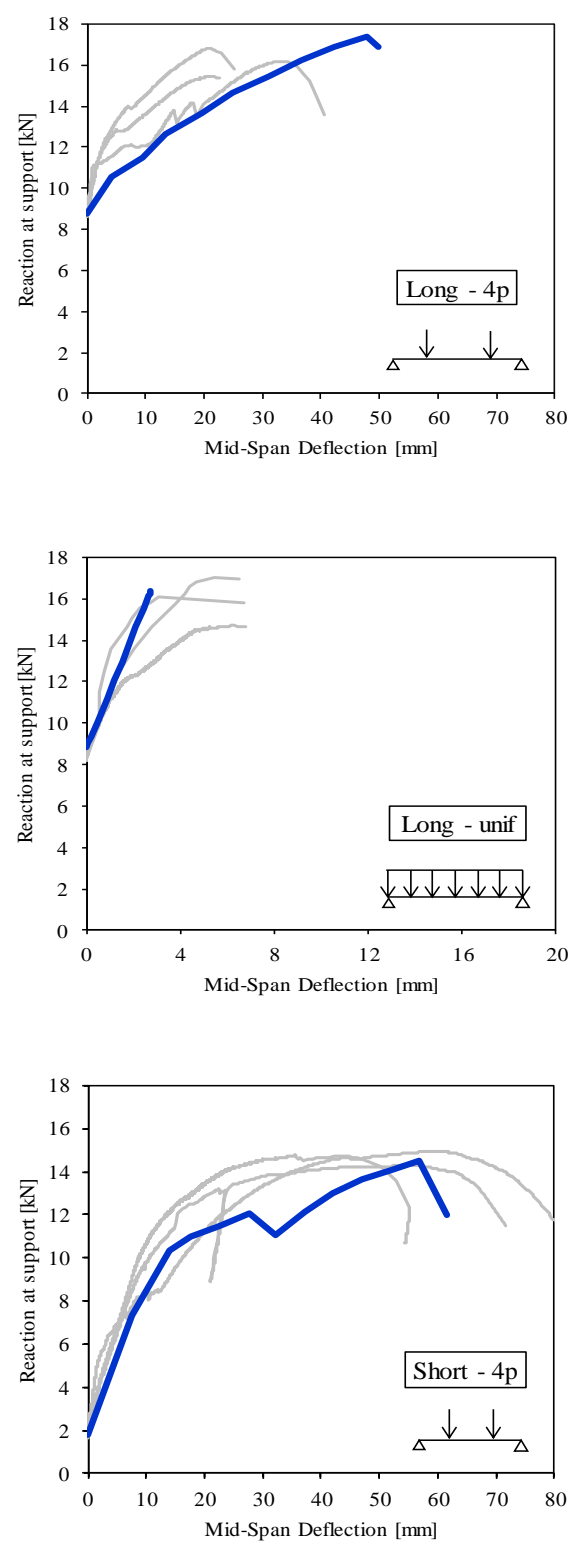

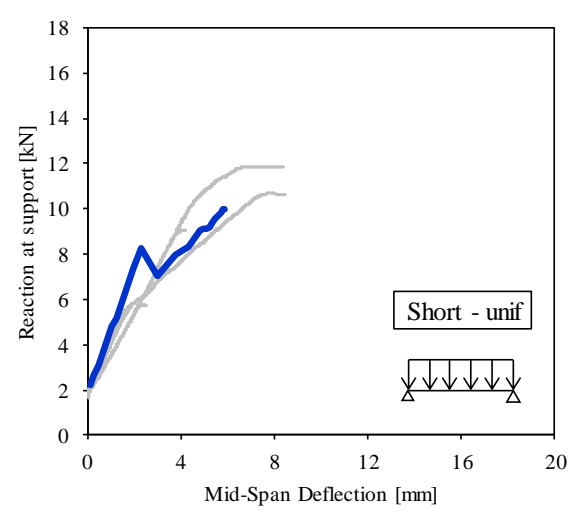

Figure 10. Shear resistance - deflection curve

\section{REFERENCES}

[1] M. Ferrer, F. Marimon and M. Casafont, "An experimental investigation of a new perfect bond technology for composite slabs," Construction and Building Materials, pp. 618-633, 2018.

[2] EN1994-1-1: European Committee for Standardization, Design of composite steel and concrete structures Part 1.1: General rules and rules for buildings, 2004.

[3] BS5950, British Standard, Structural use of steelwork in building Part 4: Code of practice for design of composite slabs with profiled steel sheeting, 1994

[4] E. Lopes and R. Simões, "Experimental and analytical behaviour of composite slabs," Steel and Composite Structures, vol. 8, pp. 361-388, 2008

[5] M. Crisinel and F. Marimon, "A new simplified method for the design of composite slabs," Journal of Constructional Steel Research, vol. 60, pp. 481-491, 2004.

[6] M. Veljkovic, "Influence of load arrangement on composite slab behavior and recommendations for design," Journal of Constructional Steel Research, vol. 45, pp. 149-178, 1997.

[7] G. Shen, "Performance evaluation of new corrugated-type embossments for composite deck," Master Thesis, Blacksburg: Virginia Polytechnic Institute and State University, 2001, pp. 3741.

[8] J. Holomek and M. Bajer, "Experimental and numerical investigation of composite action of steel concrete slab," Procedia Engineering, pp. 143-147, 2012.

[9] J. Melcher, M. Karmazínová, and P. Schmid, "Vacuum loading; Experimental verification of process of deformation and loadbearing capacity of construction members or elements using vacuum loading in horizontal metal chamber." Laboratory of regional research centre AdMaS, building $\mathrm{H}$. http://www.kdk.fce.vutbr.cz (verified technology), 2016

[10] J. Melcher, "Full-scale testing of steel and timber structures: Examples and experience, in structural assessment - the role of large and full scale testing," Edited by K.S. Virdiet. al., London: E\&FN SPON, 1997, pp. 301 - 308, ISBN 0419224904

[11] J. D. Ríos, H. Cifuentes, A. M. La Concha, and F. MedinaReguera, "Numerical modelling of the shear-bond behaviour of composite slabs in four and six-point bending tests," Engineering Structures, vol. 133, pp. 91-104, 2017.

[12] H. Cifuentes and F. Medina, "Experimental study on shear bond behavior of composite slabs according to Eurocode 4," Journal of Constructional Steel Research, vol. 82, pp. 99-110, 2013.

[13] "ANSYS® Academic Teaching Mechanical, Release 19.0," in Help System, Mechanical APDL, Element Reference. 